\title{
THE ANALYSIS OF THE USE OF DIGITAL TECHNOLOGY LEARNING MEDIA IN ELEMENTARY SCHOOLS OF CILEUNYI DISTRICT
}

\author{
Eryca Pratiwi ${ }^{1}$, Kristi Pratiwi ${ }^{2}$, Marlina Sari ${ }^{3}$, Salma Namiroh ${ }^{4}$ \\ 1,2,3,4 Universitas Pendidikan Indonesia, Bandung, Indonesia \\ ${ }^{1}$ Erycapratiwi05@upi.edu,,${ }^{2}$ kristip26@upi.edu,${ }^{3}$ marlinasari@upi.edu, ${ }^{4}$ salmanamiroh@upi.edu
}

\begin{abstract}
This study aims to analyze the use of digital technology learning media in elementary schools in the Cileunyi District. Digital technology is one proof of the development of technological progress in the 21st century. These technological advancements have influenced several fields, one of which is education. In this digital era, technology is involved in the field of education, especially in the learning process. Digital technology is now used as a learning medium. The use of digital technology as a learning medium means that the teacher has balanced knowledge with the technological advancements that occur. The research was conducted with a qualitative study by distributing questionnaires to 17 elementary schools in the district of Cileunyi. From the findings, it was known that all teachers have used digital technology as a medium of learning in elementary schools with different usage scales. The use of digital technology as a learning medium had an impact on teachers and the learning process undertaken. There were teachers who felt learning to be effective and innovative, yet there were still difficulties in using digital technology and felt the use of digital technology in elementary schools was less effective.
\end{abstract}

Keywords: digital technology, learning media, elementary school

\section{ANALISIS PENGGUNAAN MEDIA PEMBELAJARAN TEKNOLOGI DIGITAL DI SEKOLAH DASAR SE-KECAMATAN CILEUNYI}

ABSTRAK

Penelitian ini bertujuan untuk menganalisis bagaimana penggunaan media pembelajaran teknologi digital di Sekolah Dasar se-Kecamatan Cileunyi. Teknologi digital merupakan salah satu bukti dari berkembangnya kemajuan teknologi pada abad ke-21 ini. Kemajuan teknologi memberikan pengaruh terhadap beberapa bidang salah satunya adalah bidang pendidikan. Pada era digital, teknologi dilibatkan dalam bidang pendidikan khususnya dalam proses pembelajaran. Teknologi digital kini digunakan sebagai media pembelajaran. Adapun penggunaan teknologi digital sebagai media pembelajaran mengartikan bahwa guru sudah mengimbangi pengetahuan dengan kemajuan teknologi yang terjadi. Peneliti melakukan penelitian kualitatif dengan menyebarkan kuisioner ke 17 Sekolah Dasar di Kecamatan Cileunyi. Dari penelitian yang telah dilakukan, peneliti mengetahui bahwa semua guru sudah menggunakan teknologi digital sebagai media pembelajaran di Sekolah Dasar dengan skala penggunaan yang berbeda. Penggunaan teknologi digital sebagai media pembelajaran memberikan dampak terhadap guru dan proses pembelajaran yang dilakukan. Ada guru yang merasa pembelajaran menjadi efektif dan inovatif namun ada yang masih kesulitan dalam menggunakan teknologi digital dan merasa penggunaan teknologi digital di Sekolah Dasar kurang efektif.

Kata Kunci: teknologi digital, media pembelajaran, sekolah dasar

\begin{tabular}{|c|c|c|}
\hline Submitted & Accepted & Published \\
\hline 25 Februari 2020 & 13 Mei 2020 & 22 Juli 2020 \\
\hline
\end{tabular}

\begin{tabular}{|l|c|c|}
\hline Citation & $:$ & $\begin{array}{r}\text { Pratiwi, E., Pratiwi, K., Sari, M., \& Namiroh, S. (2020). The Analysis of the Use of Digital Technology Learning Media } \\
\text { in Elementary Schools of Cileunyi District. Jurnal PAJAR (Pendidikan dan Pengajaran), 4(4), 663-670. DOI : } \\
\text { http://dx.doi.org/10.33578/pjr.v4i2.8011. }\end{array}$ \\
\hline
\end{tabular}

\section{PENDAHULUAN}

Memasuki Abad ke-21 berarti menandakan semakin berkembangnya beberapa aspek dalam kehidupan dari berbagai bidang. Perkembangan terlihat jelas pada bidang teknologi yang sekarang sudah memasuki era teknologi

digital. Perkembangan teknologi pada era digital menandakan teknologi yang semakin maju. Kemajuan teknologi yang saat ini kita rasakan, memaksa kita untuk meningkatkan kemampuan diri dalam menggunakannya. Sebagai masyarakat 
yang hidup di era digital, akan merasa tertinggal jika kita tidak mengikuti arus perkembangan teknologi. Tidak semua teknologi bisa kita nilai negatif, karena jika kita menggunakan teknologi dengan bijak maka teknologi tersebut akan membawa manfaat positif dalam kehidupan kita sehari-hari. Misalnya dalam dunia pendidikan, dewasa ini sudah banyak sekali pemanfaatan teknologi yang berpengaruh positif dan bermanfaat untuk pendidikan di Indonesia, seperti Teknologi Internet (Sudiarta \& Sadra, 2016), Komputer, Andrioid, dll. Kemajuan ilmu pengetahuan dan teknologi juga berpengaruh terhadap penggunaan alat-alat bantu mengajar di sekolah-sekolah dan lembaga-lembaga pendidikan lainnya. Dewasa ini pembelajaran di sekolah mulai disesuaikan dengan perkembangan teknologi informasi, sehingga terjadi perubahan dan pergeseran paradigma pendidikan (Hujair, 2009). Hal ini mengindikasikan bahwa penggunaan teknologi informasi dalam proses pembelajaran di kelas, sudah menjadi suatu kebutuhan sekaligus tuntutan di era global ini.

Di samping berkembangnya ilmu pengetahuan dan teknologi, guru sebagai komponen utama dalam dunia pendidikan dituntut untuk mampu mengimbangi bahkan melampaui

\section{KAJIAN TEORETIS}

\section{Era Teknologi Digital}

Pada era digital atau era informasi saat ini, membawa pengetahuan dan teknologi semakin berkembang pesat. Informasi dan pengetahuan mudah diakses dan diterima dalam jarak jauh tanpa melihat batas ruang dan waktu. Oleh karena itu, dalam kehidupan diera digital ini manusia akan selalu berhubungan dengan teknologi. Teknologi pada hakikatnya adalah proses untuk mendapatkan nilai tambah dari produk yang dihasilkannya agar bermanfaat.

Digital berasal dari bahasa Yunani yaitu Digitus (Greek) yang berarti jari jemari. Dimana jumlah jari jemari 10 yang terdiri dari angka 1 dan angka 0. Oleh karena itu, digital berhubungan dengan angka dan juga sesuatu yang dianggap biner karena membentuk bilangan binner 1010101010. Digital menurut Cambridge perkembangan ilmu pengetahuan dan teknologi yang berkembang dalam masyarakat. Salah satunya adalah guru dituntut untuk menciptakan proses pembelajaran yang efektif dan inovatif, diantaranya adalah penggunanan media pembelajaran yang dilakukan seefektif mungkin dalam suasana yang menyenangkan dan penuh gairah serta bermakna. Saudagar (2009:85) mengemukakan bahwa guru merupakan kunci dalam peningkatan mutu pendidikan dan mereka berada di titik sentral dari setiap usaha reformasi pendidikan yang diarahkan pada perubahanperubahan kualitatif.

Dalam mengembangkan media pembelajaran di era digital ini, guru harus melek dan tentunya bisa menggunakan berbagai macam media untuk menunjang terlaksananya proses pembelajaran yang efektif dan mudah dipahami. Selain menguasai media pembelajaran sederhana, guru pun harus bisa menguasai dan memanfaatkan teknologi sebagai media pembelajaran dengan menciptakan media pembelajaran yang berbasis digital. Berdasarkan hal tersebut, dalam artikel ini kami membahas mengenai bagaimana penggunaan media pembelajaran teknologi digital seKecamatan Cileunyi.

Dictionary merupakan penyimpan info, bentuk teknologi dan bentuk tampilan informasi.

Teknologi digital yaitu teknologi yang dioperasikan dengan menggunakan sistem komputerisasi, sistem tersebut didasari dari bentuk informasi sebagai nilai numeris 0 dan 1 yang mengidentifikasi tombol hidup dan mati. Dilihat dari perspektif komunikasi, teknologi digital merupakan sistem penyampaian yang efisien, komunikasi menjadi lebih dinamis.

\section{Media Pembelajaran Teknologi Digital}

Media berasal dari bahasa Latin yakni medius yang artinya tengah, perantara atau pengantar. Media adalah perantara yang digunakan untuk mengantar pesan dari pengirim ke penerima. (Arief. S. dkk, 2011: 6). Hakikat media pembelajaran berawal dari ilmu komunikasi. 
Menurut K. Berto, terdapat empat komponen proses komunikasi yaitu source (sumber/komunikator/pengirim), message (pesan/informasi), channel (media/saluran) dan receiver (penerima). Oleh karena itu, media adalah saluran komunikasi, istilah ini merujuk pada apapun yang membawa pesan/informasi.

Media pembelajaran tentunya memiliki karakteristik, diantaranya pertama memiliki tujuan untuk menyampaikan pesan pembelajaran. Kedua, menyajikan pengalaman pembelajaran yang spesifik maksudnya tidak pernah ada media pembelajaran yang mencakup seluruh materi keseluruhan. Ketiga, menggunakan simbol-simbol pesan yang sesuai. Keempat, reusable yakni mampu digunakan berulang.

Media pembelajaran yang baik memiliki dua ciri yaitu relevansi yang tinggi baik secara internal dan eksternal serta memiliki added value (nilai tambah). Maksud dari relevansi atau kesesuaian media pembelajaran secara internal adalah terkait dengan komponen-komponen yang saling terkoneksi seperti tujuan pembelajaran yang akan dicapai, karakteristik materi pembelajaran yang disampaikan, strategi pembelajaran yang diterapkan dan rencana evaluasi pembelajaran yang akan digunakan. Sedangkan relevansi atau kesesuaian media pembelajaran secara ekstenal adalah terkait dengan kondisi dan karakteristik peserta didik serta ketersediaan daya dukungnya. Contoh penggunaan media pembelajaran teknologi digital di Sekolah Dasar dalam bentuk powerpoint, video pembelajaran, web-based, sosial media dan Messenger.

Video pembelajaran merupakan gambargambar dalam frame, dimana frame demi frame

\section{METODE PENELITIAN}

Metode penelitian yang dipakai adalah Deskriptif kualitatif, merupakan salah satu dari jenis penelitian yang termasuk dalam jenis penelitian kualitatif. Adapun tujuan dari penelitian ini adalah untuk mengungkapkan kejadian atau fakta, keadaan, fenomena, variabel dan keadaan yang terjadi saat penelitian berlangsung dengan menyuguhkan apa yang sebenarnya terjadi. diproyeksikan melalui lensa proyektor secara mekanis sehingga pada layar terlihat gambar hidup yang digunakan oleh guru dalam menyampaikan materi pembelajaran. Microsoft office power point merupakan program aplikasi kantor bertipe slide show (lembar kerja yang merupakan kaca objek bergantian) yang digunakan untuk mempresentasikan konsep dan argumen yang ingin ditunjukkan pada orang lain. Media sosial adalah sebuah media online yang para penggunaannya berpartisipasi dan bersosialisasi menggunakan internet. Web Based merupakan perangkat lunak berbasis web dan terkait dengan sejumlah halaman. Messenger adalah suatu teknologi jaringan yang mengijinkan penggunaannya mengirimkan pesan secara realtime ke pengguna lain yang tersambung dalam sebuah jaringan LAN atau Local Area Network ataupun internet.

\section{Penggunaan Media Pembelajaran}

Pola penggunaan mengandung konsep suatu cara atau kebiasaan dalam menggunakan sesuatu, yang dalam hal ini menyangkut media teknologi digital di Sekolah Dasar berupa power point, video pembelajaran, web-based, sosial media dan Messenger. Dalam hal ini, pola penggunaan berkaitan dengan keterlibatan atau menyangkut ruang dan waktu yang disediakan oleh guru dalam menggunakan media teknologi digital di Sekolah Dasar. Terdapat dua indikator dalam keterlibatan tersebut yaitu 1) Kebiasaan menggunakan tempat untuk mengakses media teknologi digital, 2) Lamanya waktu yang disediakan untuk mengakses media teknologi digital tersebut yang menggunakan skala rutin, kadang-kadang dan tidak pernah.

Adapun instrumen yang digunakan dalam penelitian ini berupa angket digital serta teknik pengumpulan data yang dilakukan dalam penelitian ini yaitu menggunakan angket (Kuisioner) / survey. Kuisioner yang digunakan dalam penelitian ini adalah kuisioner tertutup yakni kuisioner yang sudah disediakan jawabannya, sehingga responden tinggal memilih dan menjawab secara langsung. Partisipan dari penelitian ini yaitu 
guru-guru di Sekolah Dasar se - Kecamatan Cileunyi. Penelitian ini dilakukan selama 1 minggu pada tanggal 9 Februari sampai 15 Februari 2020. Dengan jumlah responden secara umum yaitu sekitar 45 guru dari 677 guru se-Kecematan Cileunyi. Pengambilan sampel menggunakan

\section{HASIL DAN PEMBAHASAN}

Dalam melakukan analisis pengunaan media digital oleh guru di Sekolah Dasar digunakan instrumen yang menelaah lima jenis teknik random sampling yang tersebar di 17 Sekolah Dasar baik Sekolah Negeri maupun Swasta. Analisis data dalam penelitian kualitatif dilakukan secara induktif. Yaitu dengan melakukan kegiatan reduksi data, penyajian data, pengelompokan data, serta pembuatan kesimpulan.

pengunaan media pembelajaran, diantaranya sebagai berikut:

Tabel 1. Media Pembelajaran

\begin{tabular}{c}
\hline Jenis Media Pembelajaran \\
\hline Video Pembelajaran \\
\hline Power point \\
\hline Web Based \\
\hline Sosial Media \\
\hline Messenger
\end{tabular}

Setelah dilakukan penelitian dengan menyebarkan angket berupa pertanyaanpertanyaan tentang penggunaan teknologi digital sebagai media di Sekolah Dasar maka didapatkan hasil presentase seperti tabel di atas. Jumlah Sekolah Dasar yang ada di Kecamatan Cileunyi menurut data yang kami dapatkan pada laman kemendikbud.go.id ada 56 Sekolah Dasar. Dari 56 Sekolah Dasar yang ada di kecamatan cilenyi kami menyebarkan angket (berupa google form) ke 17 Sekolah Dasar dengan jumlah responden sebanyak
45 orang. Berdasarkan data yang kami dapatkan menyatakan bahwa 34 dari 45 responden menggunakan video sebagai media pembelajaran dengan presentase pola penggunaan $55.9 \%$ pernah menggunakan sebagai media pembelajaran, 35.3 $\%$ kadang-kadang menggunakan video sebagai media pembelajaran dan $8.8 \%$ sering menggunakan sebagai media pembelajaran. Ini berarti menyatakan bahwa guru sebagian besar melibatkan teknologi digital berupa video sebagai media pembelajaran.
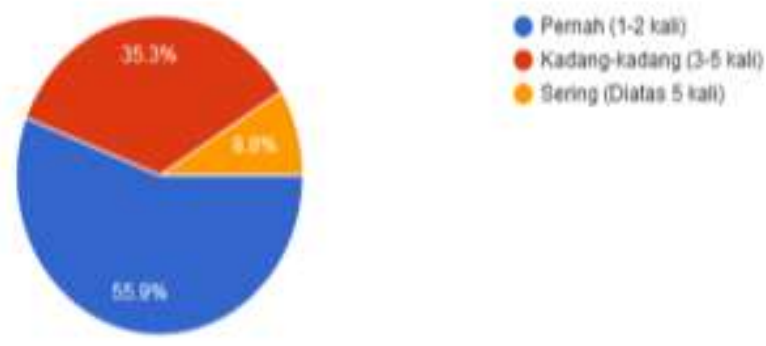

\section{Gambar 1. Presentase Penggunaan Video Sebagai Media Pembelajaran di Sekolah Dasar Se- Kecamatan Cileunyi}


Berdasarkan data yang kami dapat menyatakan bahwa 21 dari 45 responden menggunakan power point sebagai media pembelajaran dengan presentase pola penggunaan $28.6 \%$ kadang-kadang menggunakan power point sebagai media pembelajaran dan $71.4 \%$ pernah

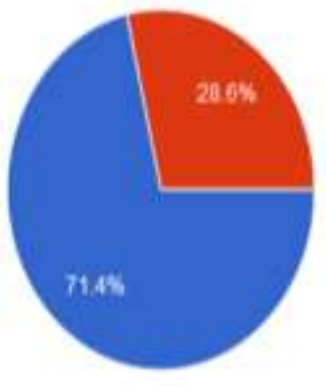

menggunakan power point sebagai media pembelajaran dan tidak ada responden yang menjawab sering dalam menggunakan power point sebagai media pembelajaran. Ini berarti menyatakan bahwa guru masih minim melibatkan power point sebagai media pembelajaran.

\section{Gambar 2. Penggunaan Power point Sebagai Media Pembalajaran di Sekolah Dasar Se-Kecamatan Cileunyi}

Berdasarkan data yang kami dapatkan menyatakan bahwa 20 dari 45 responden menggunakan Web Based (seperti aplikasi pendukung pembelajaran) sebagai media pembelajaran dengan presentase pola penggunaan $70 \%$ pernah menggunakan Web Based sebagai

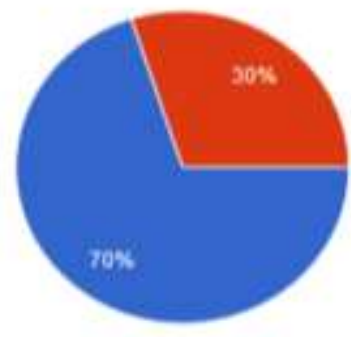

media pembelajaran dan $30 \%$ kadang-kadang menggunakan Web Based sebagai media pembelajaran. Ini berarti menyatakan bahwa tidak banyak guru yang menggunakan Web Based sebagai media pembelajaran.

\section{Gambar 3. Penggunaan Web Based Sebagai Media Pembelajaran di Sekolah Dasar Se-Kecamatan Cileunyi}

Berdasarkan data yang kami dapatkan menyatakan bahwa 33 dari 45 responden menggunakan sosial media sebagai media pembelajaran dengan presentase pola penggunaan $51.5 \%$ pernah menggunakan sosial media sebagai media pembelajaran, $39.4 \%$ kadang-kadang 
menggunakan sosial media sebagai media pembelajaran dan $9.1 \%$ sering menggunakan sosial media sebagai media pembelajaran.

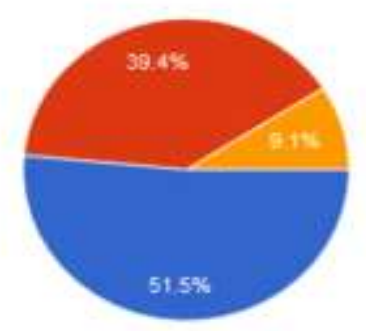

Pernah $(1-2 \mathrm{kal})$

Kadang-kadang (3-5 kal

Sering (Diatas $5 \mathrm{kal}$ )

\section{Gambar 4. Presentase Penggunaan Sosial Media Sebagai Media Pembelajaran di Sekolah Dasar Se- Kecamatan Cileunyi}

Berdasarkan data yang kami dapatkan menyatakan bahwa 22 dari 45 responden menggunakan Messenger sebagai media pembelajaran dengan presentase pola penggunaan $36.4 \%$ pernah menggunakan Messenger sebagai media pembelajaran, $50 \%$ kadang-kadang menggunakan Messenger sebagai media pembelajaran dan $13.6 \%$ sering menggunakan Messenger sebagai media pembelajaran. Ini berarti menyatakan bahwa guru-guru masih banyak yang melibatkan Messenger sebagai media pembelajaran walaupun dengan skala yang kecil.
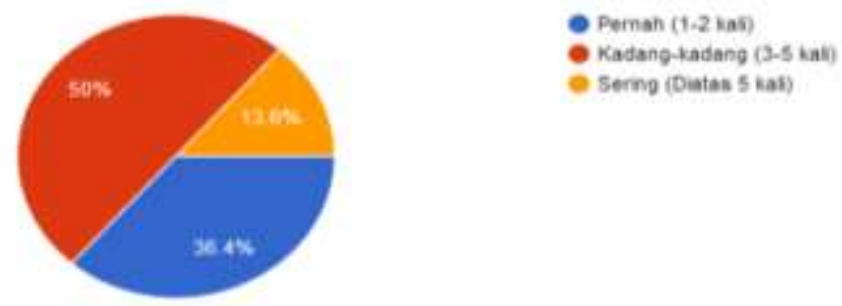

\section{Gambar 5. Presentase Penggunaan Messenger Sebagai Media Pembelajaran di Sekolah Dasar Se- Kecamatan Cileunyi}

Pada kuisioner kami juga menanyakan bagaimana pendapat guru terkait dengan penggunaan teknologi digital sebagai media pembelajaran di Sekolah Dasar. Sebagian besar dari guru menjawab bahwa teknologi digital sebagai media pembelajaran menjadikan pembelajaran menjadi lebih inovatif dan efektif. Namun demikian ada guru yang menyatakan bahwa teknologi digital sebagai media pembelajaran tidak bisa digunakan pada semua pembelajaran. Serta ada guru yang mengatakan bahwa penggunaan teknologi digital kurang tepat jika dilakukan di Sekolah Dasar dan masih ada beberapa guru yang kesulitan dalam menggunakan teknologi digital sebagai media pembelajaran.

Sejalan dengan apa yang dikatakan oleh (Sudiarta \& Sadra, 2006) bahwa dalam dunia pendidikan dewasa ini sudah banyak sekali pemanfaatan teknologi yang berpengaruh positif dan bermanfaat bagi pendidikan indonesia. Pemanfaatan teknologi yang digunakan salah satunya adalah teknologi digital dimana dari hasil penelitian ini terlihat bahwa teknologi digital dapat membantu guru dalam menyediakan media 
pembelajaran sebagai penjunjang kegiatan pembelajaran. Dengan adanya teknologi digital ini, seperti apa yang telah diungkapkan responden bahwa pemanfaatan teknologi digital sebagai media pembelajaran dapat menjadikan pembelajaran menjadi lebih inovatif. Namun disamping hal tersebut, masih ada beberapa guru atau responden yang kesulitan dalam menggunakan teknologi digital sehingga memilih untuk tidak memanfaatkan teknologi digital sebagai media pembelajaran. oleh karena itu, dengan adanya keadaan seperti ini guru harus mampu meningkatkan kompetensi dalam menggunakan teknologi digital sebagai media pembelajaran. Karena pada hakikatnya guru merupakan kunci dalam peningkatan mutu pendidikan dan mereka berada di titik sentral dari setiap usaha reformasi pendidikan yang diarahkan pada perubahan-perubahan kualitatif (Saudagar, 2009:85).

Hasil penelitian mengenai penggunaan media pembelajaran teknologi digital pada saat dilakukan penyebaran kuisioner, responden yang terdiri dari 45 guru paling banyak memilih powerpoint. Demikian dapat dikatakan bahwa powerpoint merupakan media pembelajari yang

\section{SIMPULAN DAN REKOMENDASI}

Hasil yang diperoleh dari penelitian ini menggambarkan bahwa belum optimalnya penggunaan media digital dalam proses pembelajaran di Sekolah Dasar. Meskipun begitu, penggunaan media digital seperti sosial media dan Messenger sudah mulai mendapat perhatian dari beberapa guru. Diharapkan hal ini menjadi awal terintegrasinya teknologi digital di Sekolah Dasar agar dapat mengikis keterbatasan ruang dan waktu

\section{UCAPAN TERIMA KASIH}

Kami ucapkan terima kasih kepada Bapak serta Ibu guru dari 17 sekolah di kecamatan Cileunyi yang telah dengan sukarela mengisi kuisioner penelitian yang kami berikan. Serta kami paling banyak diminati oleh guru untuk menyampaikan pembelajaran. Microsoft office power point merupakan program aplikasi kantor bertipe slide show (lembar kerja yang merupakan kaca objek bergantian) yang digunakan untuk mempresentasikan konsep dan argumen yang ingin ditunjukkan pada orang lain. Sistem pengoprasiannya yang mudah menyebabkan banyak orang dapat membuat dan menggunakan power point tersebut.

Fitur-fitur yang ditawarkan dalam power point cukup menarik seperti dapat menyisipkan gambar, audio, animasi, efek dan lainnya yang dapat menjadikan pembelajaran menjadi lebih menarik ketika disampaikan kepada peserta didik.

Media power point dipandang dapat memusatkan perhatian peserta didik pada pembelajaran. hal ini dikarenakan sebuah gambar dalam slide di power point akan lebih efektif ketimbang kata-kata saja. Ketika pembelajaran yang diberikan menggunakan dimensi auditori ditambah dengan visual pesan yang diberikan akan lebih kuat diserap oleh peserta didik, sehingga pembelajaran tidak lagi membosankan (Sulastri, 2017).

serta memvariasikan pembelajaran. Dalam mendiseminasikan teknologi digital di Sekolah Dasar juga perlu didukung dengan menghadirkan narasumber ahli pada saat kegiatan workshop atau KKG, sehingga dapat membantu guru yang sampai saat ini masih mengalami kesulitan dalam menggunakan teknologi digital sebagai media pembelajaran di Sekolah Dasar

ucapkan terima kasih kepada Bapak M. Ridwan Sutisna, M.Pd selaku pembimbing kami dalam pembuatan artikel ilmiah ini. 


\section{DAFTAR PUSTAKA}

Arief, S. Dkk. (2011). Media Pendidikan. Jakarta: PT Raja Grafindo Persada.

Ansori, S. (2010). Pemanfaatan Teknologi Informasi dan Komunikasi sebagai Media Pembelajaran. Civic-Culture : Jurnal Ilmu Pendidikan PKN dan Sosial Budaya. 2 (1), 88-100

Bodgan, R. \& Biklen, S. (1992). Qualitative Research for Education. Buston, MA: Allyn and Bacon.

Cresswell, J. (2015). Riset Pendidikan. Yogyakarta: Pustaka Pelajar.

Cresswell, J. (1998). Research Design: Qualitative \& Quantitative Approaches. Thousand Oaks, CA: Sage Publication.

Hadi, S. (2017). Efektivitas Penggunaan Video sebagai Media Pembelajaran untuk Siswa Sekolah Dasar. Tranformasi Pendidikan Abad 21.1 (25), 96

Kementerian Pendidikan dan Kebudayaan. (2020). Data Pokok Pendidikan Dasar dan
Menengah. [Online]. Tersedia : https://dapo.dikdasmen.kemdikbud.go.id/s p/3/020824 . Diakses pada 20 Februari 2020 .

Misbahudin, D. DKK. (2018). Penggunaan Power Point Sebagai Media Pembelajaran : Efektifkah?. Jurnal Wahana Pendidikan Fisika. 3 (1), 43-48.

Muhson, A. (2010). Pengembangan Media Pembelajaran Berbasis Informasi. Jurnal Pendidikan Akuntansi. 8 (2), 1-10.

Munir. (2017). Pembelajaran Digital. Bandung: Alfabeta.

Sulastri. (2017). Efektivitas Penggunaan Power Point dalam Pembelajaran PAI di SMP Tunas Dharma Waygalih Lampung Selatan Tahun Ajaran 2016/2017. Skripsi. Isntitut Agama Islam Negeri Raden Intan Lampung. 